\title{
La oposición venezolana y los medios de comunicación: la razón de su "silencio"
}

\author{
Jhosef Eduardo Meza Cuesta* \\ (jhosef_meza@yahoo.es)
}

Artículo de investigación recibido el 19/10/2014 y aprobado el 20/04/2015

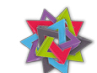

Cómo citar este artículo:

MEZA CUESTA, Jhosef Eduardo (2015). "La oposición venezolana y los medios de comunicación: la razón de su "silencio"”. En: Trans-pasando Fronteras, núm. 7, pp. 85-106. Cali, Colombia: Centro de Estudios Interdisciplinarios, Jurídicos, Sociales y Humanistas (CIES), Facultad de Derecho y Ciencias sociales, Universidad Icesi.

DOI: $10.18046 /$ retf.i7.1607

\section{Resumen}

El objetivo de este artículo es explicar por qué la vulneración de la libertad de expresión y de comunicación a la oposición venezolana ha sido la razón principal por la cual ha estado en un relativo silencio durante más de diez años. En la primera parte se expondrán las formas y los motivos por los que estas libertades han sido vulneradas por parte del gobierno venezolano; en la segunda se argumentará con más profundidad la tesis principal, analizando varios textos que tratan la problemática y explicando las implicaciones que todo esto trae no solo para los actores políticos involucrados sino para la polarizada sociedad venezolana. Por último se realizarán las conclusiones pertinentes, de acuerdo con lo desarrollado en la investigación.

* $\quad$ Estudiante de Ciencia Política de la Universidad Nacional de Colombia (Sede Bogotá D.C.). Director de la Revista Latinoamericana "Surmanía” y miembro del Semillero de Investigación No. 1 llamado "Ciudadanías juveniles y paz democrática en Colombia". 


\section{Palabras clave}

Oposición, gobierno, libertad de expresión y de información, medios de comunicación, censura.

\section{Introducción}

La década del 2000 será recordada en América Latina porque, después de décadas de dictaduras militares y posteriores transiciones democráticas, hubo una oleada de gobiernos alternativos, de los cuales, algunos aún se mantienen. A pesar de que se pueden diferenciar entre sí, sus políticas tanto como sus discursos son bastante similares: están en contra del imperialismo estadounidense - en otros casos se alejan de la influencia de los Estados Unidos, más no rompen con ellos, como es el caso de Argentina-; realizan políticas que limitan el accionar de las elites, tanto políticas como económicas, en beneficio de las clases populares mediante, por ejemplo, la estatización de empresas, especialmente las extractoras de recursos minero-energéticos; y un variado programa de subsidios que reducen la pobreza y la desigualdad social.

Solo algunos países no han tenido gobiernos de este tipo -como Colombia, México, Perú, entre otros- $\mathrm{y}$ tal vez eso se explica por la cultura política de sus respectivas ciudadanías y su correspondiente devenir histórico de las últimas décadas. A pesar de su relativa estabilidad, los gobiernos alternativos de América Latina, tiene grupos políticos que se oponen de una u otra manera a su forma de gobernar y a sus discursos, y además, han sido importantes en su contexto político. Sin embargo, durante más de diez años han permanecido en un silencio que dista de ser absoluto, aunque en algunos momentos tienden a serlo. La razón principal de este silencio es la violación de las libertades de expresión y de comunicación hacia estos grupos -que aquí en adelante se les llamará "oposición"que se ha realizado por parte de dichos gobiernos en los últimos años.

Aquí vale la pena resaltar que algunos casos son más relevantes que otros; un ejemplo clásico podría ser el de Ecuador, que recientemente aprobó una ley de medios de comunicación que es calificada de "mordaza" por varios organismos internacionales -como la Comisión Interamericana de Derechos Humanos (CIDH)-; y otro podría

1 "Mordaza" es una palabra adoptada por aquellos que denuncian limitaciones o prohibiciones a la libertad de expresión; es una metáfora: las leyes y medidas adoptadas con tales fines son como si fueran una trozo de tela o una soga que es puesta en la boca de alguien para impedir que hablen, que se conoce con tal nombre. 
ser el de Argentina, que también hizo lo propio hace cuatro años pero aún no ha entrado en vigencia porque los altos tribunales del país la consideraron inconstitucional hace unos meses (Vanguardia Liberal, 12 de Julio de 2013). Sin embargo, las organizaciones internacionales, las ONG que tratan los temas relacionados con los medios de comunicación y varios académicos, concuerdan en que el caso más paradigmático de todos es el de Venezuela.

Entre las razones por las cuales se escogió este país para tratar la problemática de la libertad de expresión y de comunicación están: la sistemática violación de estas libertades por parte del gobierno venezolano al aplicar leyes que acallan las voces opositoras al régimen. Y, la imposición de drásticas sanciones a los medios de comunicación que disten de lo establecido. También por el contexto político, pues Venezuela se caracteriza por ser un país extremamente polarizado, algo que se reafirmó e intensificó con la controversial elección del presidente Nicolás Maduro. Por lo que cualquier cosa que se dice en los medios de comunicación, ya sean estatales o privados, provoca $-\mathrm{y}$ ya ha provocado varias veces- situaciones tensas entre el gobierno y la oposición; por último, y como causa de lo anterior, ha surgido una oposición más fuerte y unida, por lo que el chavismo ha intentado acallar su voz para impedir que se convierta en un gran rival en el ámbito político.

Por estas razones, el objetivo de este artículo es explicar por qué la vulneración de la libertad de expresión y de comunicación a la oposición venezolana ha sido la razón principal por la cual ha estado en un relativo silencio durante más de diez años. En la primera parte se expondrán las formas y los motivos por los que estas libertades han sido vulneradas por parte del gobierno venezolano; en la segunda se argumentará con más profundidad la tesis principal, analizando varios textos que tratan la problemática y explicando las implicaciones que todo esto trae no solo para los actores políticos involucrados sino para la polarizada sociedad venezolana. Por último se realizarán las conclusiones pertinentes, de acuerdo con lo desarrollado en la investigación.

\section{La libertad de expresión en Venezuela: un privilegio de unos pocos}

Una explicación plausible para este apartado es que hay una contradicción entre los objetivos que tiene el gobierno venezolano al promulgar leyes de medios de comunicación 
y la realidad. Se hace necesario explicar desde el punto de vista de varios autores cuáles han sido los mecanismos por los que se han vulnerado las libertades de opinión y de comunicación en aquel país.

Hay un consenso entre los académicos que tratan el tema, convergen en que las tensas relaciones entre el Estado y los medios privados de comunicación comenzaron en Abril de 2002 cuando ocurrió el Golpe de Estado contra Hugo Chávez (presidente desde 1998) después de una grave falta de legitimidad que tuvieron tanto los partidos políticos como el gobierno y los mismos medios privados, que controlaban casi toda la radio y la televisión (Castillo Briceño, 2003; Campbell, 2012). Después de lo ocurrido, el mandatario acusó a estos de ser parte del golpe debido a que realizaron un "falso" cubrimiento de los hechos y legitimaron al gobernante interino, Pedro Carmona -que por cierto, solo duró en su cargo unas 48 horas- (Castillo Briceño, 2007). Desde ese entonces empezaron a aplicarse una serie de mecanismos que tenían como objetivo real la limitación de la libertad de expresión y de comunicación hacia la oposición. Según los autores consultados, básicamente son: leyes, creación de nuevos medios e investigaciones individuales.

\section{Leyes}

Una primera medida que adoptó la Asamblea Nacional de Venezuela fue la aprobación y promulgación de la Ley de Responsabilidad Social de Radio y Televisión -más conocida como "Ley Resorte"-, que prohíbe la transmisión de contenidos que: primero, hagan apología al delito; segundo, muestren imágenes obscenas que puedan afectar la salud mental de los menores de edad; tercero, que inciten a tas alteraciones det orden público; y cuarto, que no reconozcan a las autoridades democráticamente establecidas. En 2010 fue ampliado el alcance de esta ley, que ya involucra también al internet y a la censura previa, que puede ser ejercida por la Comisión Nacional de Telecomunicaciones (CONATEL) (Campbell, 2012).

A lo largo de casi nueve años de su promulgación, y casi tres de su ampliación, esta ley ya ha sido aplicada no tanto a los medios que están al servicio del chavismo, sino sustancialmente a la oposición. Un informe de la ONG Human Rights Watch publicado en 2012 llamado Concentración y abuso de poder en la Venezuela de Chávez revela que varios medios que tenían una línea editorial crítica al gobierno fueron multados y/o clau- 
surados por la Comisión. Dos casos son los más relevantes: Radio Caracas Televisión y Globovisión, que fue hasta hace unas pocas semanas el único canal de televisión que se oponía al chavismo. Todo en función de dicha ley.

El primero, que durante más de cincuenta años fue el canal más visto en Venezuela, fue clausurado en mayo de 2007 y reemplazado por la televisora estatal Tves por publicar una noticia en la que el Ministro de Energía de Chávez del momento aparecía ante los empleados de la compañía de petróleos del Estado (Petróleos de Venezuela S.A., PDVSA) advirtiéndoles que debían apoyar las políticas del gobierno, o de lo contrario deberían renunciar a sus empleos (Human Rights Watch, 2012). Durante los años siguientes, este canal transmitía por señal de cable, llamándose Radio Caracas Televisión Internacional. Este también fue clausurado por el gobierno debido según este, a que violaba la normatividad adoptada por CONATEL, específicamente a aquella que determinaba que los canales de producción nacional debían ajustarse a dichas normas. Como RCTV Internacional lo era, según una determinación de la comisión, tuvo que suspender su transmisión en 2010 y desde ese entonces solo se puede ver a través de internet (Ibídem).

El segundo fue hasta hace unas semanas el único canal de televisión con línea crítica del gobierno venezolano ya que fue comprado por un empresario afin al chavismo (El Espectador, 2 de Mayo de 2013; El Tiempo, 13 de Mayo de 2013). Globovisión, que fue, al igual que el anterior, uno de los más vistos, no ha sido clausurado -y es poco probable que lo sea, por obvias razones-, pero si ha tenido que pagar multas por, simplemente, violar la Ley Resorte. Todo empezó en 2011 cuando hubo un motín en la cárcel El Rodeo, cerca de Caracas, en la que hubo tensión ya que la fuerza pública y los manifestantes se enfrentaron fuertemente, provocando varios muertos. El cubrimiento que se hizo por parte de este canal se consideró por el gobierno como algo que hacía apología al delito, provocaba inestabilidad en la población y la incitaba al desorden público; el reportero del canal mostró varias imágenes en las que la policía ejercía la fuerza y disparaba gases lacrimógenos, y entrevistó a varias personas que estaban preocupadas por los hechos y el estado de sus familiares internos. Según la ley, si un medio la violaba debía pagar una multa equivalente al 7.5\% de la ganancia obtenidas ese año. En efecto, Globovisión debido a una sentencia de la Fiscalía General de Venezuela, pagó 2.2 millones de dólares al gobierno del país (Human Rights Watch, 2012). 


\section{Creación de nuevos medios}

Una de las características del régimen de Hugo Chávez a lo largo de su mandato fue la creación de nuevos medios controlados por el Estado. Antes de su llegada al poder en 1998, casi todo el espectro de radio y televisión fue controlado por el sector privado; este oligopolio, junto con la crisis política que se vivía en ese entonces, permitió que estos se convirtieran en actores políticos muy influyentes en la medida en que imponían la agenda política del país (Bacalao, 2009). Así permanecieron las cosas hasta 2002, cuando ocurrió el mencionado golpe de Estado.

Acompañado por la clausura y las sanciones monetarias que se aplicaron a los medios opositores, el gobierno venezolano creó varios medios "alternativos" de comunicación que son controlados totalmente por el Estado. En la televisión, solo había un canal estatal importante, Venezolana de Televisión (VTV). Según Emilia Bermúdez, en 2007 habían ya cuatro televisoras más en manos del Estado, que son, aparte del anterior: Asamblea Nacional Televisión (ANTV), Ávila TV, TVES, y el caso más conocido, Televisión del Sur (Telesur) que es un canal internacional que se emite en América Latina, parte de los Estados Unidos y Asia y Europa Occidental (Bermúdez, 2007; García Nivia, 2008). Todos ellos se han caracterizado; por tener una línea editorial plenamente a favor del gobierno de Chávez. De hecho, una de las críticas que hacen varios académicos venezolanos es que el presidente ha utilizado estos medios para ser el que más aparece en televisión, con un total de 90 minutos diarios desde 2007 (Pasquali, 2007). Una de las posibles razones para esta crítica es que desde allí ha pronunciado diatribas en contra de la oposición y ha tomado medidas a partir de ello. En la radio, el régimen ha realizado una política que promueve la creación de radios comunitarias, a la vez controladas por este. En los últimos años se han creado más de 15 emisoras de radio comunitarias a favor del gobierno (Bermúdez, 2007).

\section{Investigaciones individuales}

En parte, de acuerdo con la Ley Resorte, pero también apelando a otros argumentos, las instituciones judiciales de Venezuela han investigado individualmente a personas que trabajan en o para los medios opositores. Según el informe mencionado de Human Rights Watch, tres son los casos más importantes, todos de Globovisión: Guillermo Zuloaga, presidente del canal, Nelson Mezerhane, propietario, y Oswaldo Álvarez, comentarista. 
El primero ha sido el más grave porque ha involucrado delitos graves, en cuyo caso se remite a la inflación de precios de varios automóviles comprados, según el gobierno, por él y su hijo. El informe menciona que las investigaciones individuales en su contra se iniciaron en 2010 cuando Zuloaga, en una conferencia de la Sociedad Interamericana de Prensa (SIP), condenó las medidas tomadas por el presidente Chávez sobre la televisora Radio Caracas Televisión (RCTV), su intento de monopolizar los medios de comunicación, y su reacción durante el golpe de Estado de 2002. Unos días después hubo una respuesta oficial de la Asamblea Nacional, en la que se acusaba a él y a Globovisión de haber participado en ese acontecimiento y de realizar acusaciones falsas en contra del presidente. La Fiscalía General empezó inmediatamente una investigación y levantó un pliego de cargos por delitos, tales como la difusión de información falsa y las ofensas al jefe de Estado. Dos días después fue arrestado. Posteriormente fue acusado de otros delitos como la cacería ilegal de animales y, ya mencionado, la venta irregular de automóviles. En la actualidad, ellos viven exiliados en los Estados Unidos (Human Rights Watch, 2012).

Nelson Mezerhane también fue investigado, como el anterior, por realizar un comentario en contra del gobierno venezolano. Como propietario de un banco, fue entrevistado por un diario especializado en temas financieros en el que elogió la política monetaria del gobierno pero afirmó que varios de sus miembros difundieron rumores que provocaron el retiro masivo de ahorros bancarios. Luego de la entrevista, el presidente Chávez dijo en un discurso que esta persona no tenía el derecho de transmitir mensajes que eran irresponsables y muy graves, y solicitó una investigación contra él. La Fiscalía lo acusó de delitos bancarios como la difusión de información falsa, conspiración y malversación de fondos públicos. Además, embargo todas sus propiedades y cuentas bancarias (Ibídem).

Oswaldo Álvarez Paz, antiguo gobernador del estado Zulia, afirmó en un programa de Globovisión que el gobierno venezolano debía investigar los vínculos existentes entre varios de sus miembros y los grupos terroristas ETA y FARC, aunque el implicado resulte el mismo jefe del Estado. Hizo este comentario porque, en aquel momento, una sentencia de un tribunal español mencionaba que había posibles vínculos entre estos grupos armados y el gobierno venezolano, y en varios medios apareció el presidente de 
España, José Luis Rodríguez Zapatero, exhortando a Venezuela a realizar las investigaciones pertinentes. Luego de sus afirmaciones, dijo que Chávez no era un demócrata y su comportamiento era subversivo. Después sostuvo que el territorio venezolano se había convertido en un sitio importante para el narcotráfico. Posteriormente al programa, el presidente dijo en televisión que las acusaciones del comentarista no se podían permitir, y pidió apoyo a los poderes del Estado para investigarlo y sancionarlo. Unos días después, Álvarez Paz fue arrestado y acusado de conspiración, difusión de información falsa, e instigación pública a delinquir. Fue condenado a dos años pero podía cumplirlos bajo el régimen de libertad condicional (Ibídem).

Lo que se puede deducir y afirmar de estas investigaciones individuales es que partieron de un comentario que fue considerado como amenazante por parte del gobierno venezolano. A partir de eso se realizaron varias acusaciones que, en cierto modo, se basaron en lo establecido por la Ley Resorte. En el caso de Guillermo Zuloaga y de Nelson Mezerhane hubo otras que no tenían nada que ver con la vulneración de la libertad de expresión. El informe de la ONG no explica las razones por las que se hizo esto, pero se podría sostener que, en gran medida, lo que se buscabanem con estas era hacer ver a los acusados como peligrosos delincuentes, lo que les restaría legitimidad ante las audiencias y así, los medios de la oposición se debilitarían. Además, conseguirían que se consideren las investigaciones como corrientes, omitiéndose de esta manera su verdadero trasfondo político.

\section{Los medios de comunicación y su vinculación con el poder}

Al principio del anterior apartado se mencionó una contradicción entre las medidas adoptadas por el gobierno venezolano y la realidad política del país. Para entenderla simplemente hay que partir de sus objetivos; de su lectura se deduce que, para el mismo régimen, se buscan varias cosas, como la protección de la niñez y garantizar el orden público y la estabilidad, como también crear un clima de respeto hacia las autoridades y de tolerancia política - hay que tener en cuenta que una de las disposiciones de la Ley Resorte es impedir la emisión de contenidos que fomenten el odio (Ibídem)-, pero la realidad es muy diferente: simplemente basta con leer la prensa escrita o digital, ver los noticieros de televisión y escuchar programas de análisis en la radio, especialmente cuando hay una 
situación en Venezuela, para darse cuenta que el discurso que manejan los funcionarios estatales está en contra de los objetivos que buscan alcanzar ya que muestran a la oposición como un enemigo al que hay que combatir -y viceversa-. Esta es la razón principal por la que, durante más de diez años, esta ha estado en un relativo silencio: porque, a partir de las medidas adoptadas para los medios de comunicación y su aplicación, se ha intentado acallar la voz de la oposición.

Hay que distinguir tres puntos de vista para sustentar esto: por un lado, hay que analizarla desde los estudios que se han realizado desde hace más de cincuenta años sobre los efectos que tienen los medios de comunicación sobre las audiencias, sin dejar de lado aquellos que pueden ser provocados por la vinculación con el Estado; por otro, se debe tomar en cuenta en qué consisten las libertades de expresión y de comunicación, tanto en la teoría existente como a la luz del derecho internacional, especialmente este último ya que ha sido, en cierto modo, más explícito al respecto; y por último, a partir de los dos anteriores puntos, se puede responder mediante un estudio del contexto mediático y político que ha caracterizado a ese país desde, antes de la llegada al poder del presidente Chávez.

Los estudios sobre los efectos de los medios de comunicación son relativamente recientes debido a que, en parte, la televisión y la radio son los medios de comunicación que aparecieron en las sociedades occidentales hace poco tiempo, tomando en cuenta la antigüedad que tiene la prensa escrita -a pesar de todo, el primer estudio fue hecho en 1940-. Según el autor francés Francis Balle, desde el principio, hubo una división entre los académicos que afirmaban que, gracias a la pasividad de las audiencias frente a los medios de comunicación, desarrollados junto con la cultura de las masas, su objetivo primordial era homogeneizar a las sociedades en torno a esta, y otros que los pueden utilizar para desafiar al orden establecido (Balle, 1994). La divergencia a esta tesis vino de un autor citado por Enrique Sánchez Ruiz quien sostiene que, citando a varios autores, en muchos casos, la influencia de los medios de comunicación sobre las masas es inexistente, o por lo menos es indirecta (Sánchez Ruiz, 2005).

El primero de estos tipos de estudios fue desarrollado principalmente, según el autor francés, por Jacques Ellul. Él propone en su texto que el propósito de los medios masivos de comunicación es crear una masa homogénea que comparta los ideales de consumismo 
que impone el capitalismo, y para ello requiere de la difusión de la propaganda la cual es susceptible de llegar a la mayor cantidad de personas posible. Para alcanzar este objetivo, se deben tener ciertas condiciones: primero, debe haber un régimen que favorezca el individualismo, por otro lado, que no impida a las personas pertenecer a unos grupos específicos, esto sucede porque a los individuos se les puede transmitir la propaganda fácilmente, y porque estos grupos la pueden utilizar para difundir sus ideas. Además, también debe existir un régimen capitalista que no solo permita sino que garantice una equitativa redistribución de la riqueza, y por tanto, la reproducción y estabilidad de las clases medias; para Ellul, estas son más susceptibles de ser influenciadas por la propaganda de la comunicación de masas porque poseen más tiempo para dedicar a los asuntos políticos y las clases populares no tienen ni la capacidad intelectual ni la disponibilidad de tiempo para esto (Balle, 1994).

Analizando este párrafo, el autor se equivoca en varias cosas: primero, en el aspecto económico es posible que la propaganda de los medios de comunicación de masas llegue más a las clases medias y altas, pero no por estas razones, sino porque tienen la disponibilidad de recursos monetarios para consumir los productos que son ofrecidos mediante la publicidad; si se habla en términos políticos, es menos probable que eso ocurra, porque, al ser clases con mejor acceso a la educación y a la cultura, no pueden ser tan fácilmente manipuladas por la propaganda, pero si pueden ser parte de la discusión de los asuntos políticos. Y segundo, relacionado con lo anterior, las clases populares, al poseer pocos recursos económicos, no tener un acceso fácil a la educación y a la cultura -o en otros casos, no poseer ninguna posibilidad- y mucho menos una cultura política racional pueden ser fácilmente influenciados por una propaganda política que sea básicamente demagógica. Todo ello ocurre especialmente en los países subdesarrollados, donde la historia ha comprobado no solo la existencia de líderes carismáticos -en términos weberianos- y desigualdad en la educación, sino también la estrecha relación entre estos y los medios de comunicación.

Pero si hay un aspecto que cabe resaltar muy bien, y es el objetivo de la homogeneización de las sociedades. Cuando los medios de comunicación son monopolizados por uno u otro actor, puede ocurrir que, si este es privado, se trivialice la información para hacer que crezca el número de espectadores en búsqueda de mayores ganancias 
monetarias, y si este es el Estado, y además concentra más y más su monopolio, solo quiere imponer una ideología y una forma de pensar a la población (Gómez Buendía, 2004). Sánchez Ruiz resalta que eso ocurre solamente en los países cuyas democracias son débiles porque en estos, los medios de comunicación se convierten en instrumentos de poder de los gobernantes, mas no en las democracias fuertes porque en ellas si hay la posibilidad de que estos sean independientes aunque sean controlados por el mismo Estado (Sánchez Ruiz, 2005).

Una democracia débil, partiendo de lo que dice Guillermo O'Donnell sobre lo que es una democracia fuerte, se puede caracterizar por tener instituciones estatales poco eficaces y marcadas por la corrupción; inestabilidad política, manifestada en un frecuente cambio de gobiernos o en alteraciones al orden público por motivaciones políticas (O’Donnell, 2007); no necesariamente una economía débil, pero si una fuerte desigualdad social; falta de libertades políticas, como la libertad de expresión (Ibídem); y un aspecto muy importante: una cultura política en la población que sea tradicional, es decir, que sea favorable a la legitimidad carismática y no a la racional, que no preste atención a la libre y racional elección ni a lo establecido por la ley, sino al carisma que puede tener cierto líder (Weber, 1987).Cuando un país tiene tal contexto, también puede tener una fuerte influencia de los medios de comunicación que, en muchos casos, son controlados por gobiernos autoritarios o democracias débiles con dichas características.

Los principios básicos de la teoría liberal de los medios de comunicación afirman que estos tienen la función principal de ser el espacio en el cual las personas tengan la posibilidad de discutir las problemáticas que más aquejan a sus respectivas sociedades, y además, puedan emitir libremente su opinión (Gómez Buendía, 2004). Todo lo contrario ocurriría cuando existe un monopolio por parte de los consorcios privados o del Estado, ya que estos tratarán de imponer los contenidos que beneficien al mercado o al régimen de turno. Si su concentración se hace de manera muy fuerte, los medios de comunicación ya dejarían de ser los espacios de discusión que deberían sino que se convierten en simples instrumentos de poder (Ibídem). Ya la gente no tendrá la posibilidad de manifestarse sin temor a represalias; pero estas pueden ser diferenciales ya que la naturaleza de la concentración en si misma lo es: en cuanto al Estado, si este funciona en una democracia débil o en un régimen totalitario, lo que ocurriría, probablemente, es la aplicación medidas que restrinjan dicha posibilidad. 
Ese es un punto primordial: para que los medios masivos de comunicación sean, los espacios en los cuales las personas puedan manifestarse y discutir debe haber no solo un Estado liberal en términos formales, sino también una democracia fuerte que no solo promueva sino que garantice dos libertades fundamentales: la libertad de expresión y la libertad de comunicación. Sin ellas, no puede existir todo lo dicho.

Un autor argentino, profesor de la Universidad de Buenos Aires, llamado Damián Loreti, hace una suerte de recopilación de casi todo lo que se ha escrito sobre estas dos libertades, tanto en la teoría como a la luz del derecho internacional, haciendo énfasis en lo que se ha hecho en América Latina. En varios tratados sobre derechos humanos que se han firmado hasta los años noventa, el principio de la libertad de expresión incluye otras como la libertad de prensa y la libertad de información, pero todos ellos tienen aspectos comunes: la primera consiste en la libre escogencia de los medios para manifestar alguna información o ideología sin ninguna dificultad, y esta última consiste, básicamente, en la libertad de difundir, recibir y escoger información sin ningún tipo de presiones que hagan agentes externos (Loreti, 2005). El autor reconoce que esta es más completa porque, a pesar de que la primera las incluye a casi todas, el desarrollo del derecho internacional en materia de comunicación se ha desarrollado al respecto desde la década de los años sesenta. Aunque eso es cierto, hay autores que sostienen que hacen faltas algunas cosas que se han omitido a lo largo de los años. Por ejemplo, uno de los autores más reconocidos en Venezuela que habla sobre el tema, Antonio Pasquali, afirma que alos conceptos de libertad de expresión y de información deben complementarse e incluir la igualdad de condiciones para recibir, difundir y escoger información; él dice esto con el argumento de que no hay dicha igualdad porque hay actores que son tan poderosos que llegan, incluso, a tener más posibilidades de gozar esta libertad que las demás personas (Pasquali, 2007). En pocas palabras, terminan limitando dichas libertades, como ya se había dicho anteriormente.

A pesar de que la teoría y el derecho internacional manejan conceptos amplios, también imponen límites que son similares a los de la legislación venezolana debido a que afirman que las libertades también implican responsabilidad en su atribución: la información no debe favorecer las alteraciones del orden público; se debe tomar en cuenta otros derechos fundamentales como la honra y el buen nombre; hay prevalencia en los 
derechos de la infancia y adolescencia; se considera a la propaganda que promueve la intolerancia por motivos de raza, religión, lengua u origen nacional como un acto que puede ser castigado por la ley (Loreti, 2005). Lo que se puede decir al respecto de manera resumida es que la libertad de expresión y de información no puede ser absoluta porque, en términos de lo dicho, pondría en riesgo los regímenes democráticos, o peor aún, crearía un ambiente de hostilidad dentro o entre los países.

¿Por qué el gobierno de un país impondría límites a la libertad de expresión? En sí, se podría decir que hay dos objetivos primordiales: impedir que los grupos opositores utilicen los medios de comunicación para tener influencia en la población, y así, determinado régimen esté en riesgo de ser desafiado y/o derrocado; y garantizar la imposición de una ideología política a la población sin mayores dificultades. Ahí el contexto político, social y económico de un país, junto con la cultura política de la ciudadanía, se convierten en variables determinantes para saber si los controles a los medios de comunicación ejercidos por las democracias débiles y/o los regímenes totalitarios han dado resultado para alcanzar estos objetivos.

Esa es la contraparte a los estudios de medios que concluyen que es estos no tienen ninguna influencia o la tienen de manera indirecta: ${ }^{2}$ en los años cuarenta y cincuenta, los análisis realizados por un autor alemán de apellido Tchakothine afirman que en los países donde hay dictaduras, tomando como ejemplo la Alemania Nazi, los medios de comunicación, que son controlados por el Estado, tienen mayores efectos directos ya que utilizan aspectos cotidianos - de hecho, también instintivos, propios de la naturaleza humana-y discursos más irracionales que argumentativos para hacer que la gente, guiándose por sus sentimientos y no por la razón, adopten una ideología (Balle, 1994). Sin embargo, lo que los autores no toman en cuenta es, primero, que la erradicación de las formas de pensar diferentes a la predominante sería efectiva con la prohibición de la libre expresión y comunicación, como en efecto ocurrió en Alemania, y segundo, el por qué

2 Los estudios más relevantes fueron hechos entre los años 40 y 60 del siglo pasado. El más importante, el de Paul Lazarsfeld que analizó a una población de un estado de los Estados Unidos en época electoral, concluyo que la influencia de los medios de comunicación la ejercían de manera indirecta, es decir, las personas que más están atentas a estos adquieren un conocimiento tal que pueden convencer a otros de lo que escucharon en la radio o leyeron en el periódico. En los 60's las conclusiones de los estudios que ya involucraban a la televisión sostienen conclusiones similares. 
esas ideologías fueron adoptadas en ese momento y no en otro; para ello es importante analizar el contexto del país donde una ideología política es diseminada de manera viral entre la gente y las posibles causas por las cuales surgen los líderes carismáticos que son capaces de mover a las masas.

En Venezuela, antes de la llegada de Hugo Chávez al poder, este contexto, tan favorable al surgimiento de este tipo de personalidades, es ilustrativo: aquel país, según los autores citados al principio, pasó por una crisis económica en los años ochenta que hizo que aumentara la inflación y la pobreza, provocando un acontecimiento en la que la gente salió a protestar por la situación en 1989, un evento conocido como el Caracazo (Castillo Briceño, 2003); después, en 1992, Chávez, que en aquel momento era oficial del ejército, comandó un golpe de Estado en contra del presidente Carlos Andrés Pérez, el cual fracasó, por lo que los golpistas tuvieron que pasar algún tiempo en la cárcel, hasta que fueron indultados por el siguiente gobernante; y a finales de la década de los noventa, los partidos tradicionales -la Alianza Democrática (AD) y el Comité de Organización Política Electoral Independiente (COPEI) - tenían una mala reputación entre la ciudadanía ya que no habían logrado solucionar los problemas que aquejaban la gente como el desempleo, la corrupción y la desigualdad social (Ibídem). ${ }^{3}$ Incluso, ante todo esto, los medios de comunicación, que en esa época estaban controlados por el sector privado, también estaban deslegitimados porque, ante la debilidad del gobierno y de los partidos políticos, se convirtieron en actores políticos que imponían la agenda que se debía tratar en el país (Bermúdez, 2007).

No se puede decir que todo cambió con la llegada al poder de Chávez porque, en un principio, solo fue elegido por la falta de alternativas en las elecciones de 1998. Además, los medios de comunicación ofrecieron cierto apoyo al nuevo gobierno. Como se mencionó al principio, todo empezó en 2002 con el golpe de Estado en su contra. Por ello, el contexto mencionado anteriormente sirvió para que él subiera al poder, pero este, junto con el control a los medios de comunicación que se desarrollarían desde 2004 con la promulgación de la Ley Resorte, sirvieron -y aún sirven- para mantener tanto a Chávez como a la "revolución bolivariana" en el poder por mucho tiempo.

3 Para mayor información sobre la ruptura del sistema de partidos, ver Alejandra Arias García (2012). 
Es cierto, y hay que admitir, que las limitaciones a las libertades de prensa y comunicación no han sido las únicas formas en las que se ha intentado acallar a la oposición; una de las formas más importantes, y en las que el gobierno venezolano ha tenido un relativo éxito, es el apoyo de la gente al régimen chavista mediante una serie de programas que han reducido la pobreza y la desigualdad en la población como la estatización de empresas para la obtención de ingresos públicos -como la petrolera estatal Petróleos de Venezuela S.A. (PDVSA)- para financiar programas sociales (BBC, 7 de Marzo de 2013). Lo que han logrado estos programas son la participación de la gente en la política, la reducción de la pobreza, y por supuesto, el apoyo de las personas al régimen de Chávez tanto en las elecciones de 2006 como en las de 2012, en las que este ganó por un amplio margen (El País, 9 de Octubre de 2012). También vale la pena recordar que hace unos meses, después de la polémica elección de Nicolás Maduro como presidente de Venezuela, hubo una seria denuncia por parte de la oposición, que decía que se hizo fraude, partiendo del hecho que la diferencia entre este y el candidato opositor Henrique Capriles fue de tan solo 250 mil votos, es decir, poco más del $1 \%$ de los obtenidos en la elección. A partir de ese entonces, la Asamblea Nacional, controlada por el chavismo, ha impedido que los diputados opositores se manifiesten ahí (El País, 1 de Mayo de 2013). ${ }^{4}$

A pesar de estas y otras medidas adoptadas, el silencio de los grupos opositores ha sido relativo por las siguientes razones: primero, porque estos han buscado la forma de hacerse escuchar, así sea por medio de las redes sociales -en las que el líder opositor, Capriles, tiene más de tres millones de seguidores en Twitter (El Espectador, 12 de Julio de 2013)- o acudiendo a otros gobiernos para manifestarse -aquí es relevante resaltar la visita del líder opositor a Bogotá para buscar apoyo por parte del gobierno colombiano, algo que desató una crisis diplomática que se resolvió la semana pasada sin ningún contratiempo (El Tiempo, 23 de Julio de 2013)-. Además, han utilizado los pocos medios que tienen para expresarse ante la ciudadanía venezolana -los periódicos opositores más importantes han sido El Universal y El Nacional, ambos de Caracas, que, a pesar de las medidas adoptadas por la Asamblea

4 De hecho, unos días después de la elección de Maduro como presidente, luego de que la oposición expusiera una pancarta que decía "Golpe al parlamento" en la Asamblea Nacional, empezó una gresca en la que un diputado chavista golpeó a varios colegas de la oposición. Al final, fueron heridas once personas. 
Nacional, han seguido funcionando- En pocas palabras, el gobierno venezolano ha utilizado varios mecanismos para convertirse en una fuerza política hegemónica en su país, pero los resultados solo han sido relativos, solo .Basta con analizar un poco la situación actual en Venezuela para darse cuenta que, a pesar de dichos mecanismos, el país está polarizado en dos bandos que al parecer no se reconciliarán pronto.

Para eso se han restringido las libertades de expresión y de comunicación: para expandir sin mayores dificultades el "socialismo del siglo XXI" y no dejar que la oposición gane terreno. Por supuesto, esto ha traído consecuencias que pueden hacer mucho daño a la democracia como tal en el país, como las siguientes:

1. La gente ya no podrá tener la posibilidad de obtener información veraz e imparcial. De la lectura del informe mencionado de Human Rights Watch, y de otros publicados por el Comité para la Protección de los Periodistas (CPJ, en inglés) se deduce que lo que está ocurriendo en Venezuela tiene una implicación inmediata, y es que, al solo haber información sesgada por parte del oficialismo -y también de la oposición- la gente ya no tiene acceso a la información veraz y objetiva: por un lado, la oposición ya no posee la capacidad de cubrimiento de las noticias importantes, y por su mismo sesgo ya no hablan con imparcialidad, por lo que se hace difícil hablar sobre hechos concretos, y por otro, el chavismo trata de impedir que surjan informaciones que pongan en "riesgo" su proyecto político (Campbell, 2012). Esto es peligroso para la democracia porque las personas no sabrán cual es la gestión de su gobierno, y claro, al no tener la información completa no existirá ese debate para la solución de los problemas que aquejan al país sino que todo, como se dice comúnmente, se impondría "desde arriba".

2. Se promueve un proyecto político hegemónico que puede cultivar un terreno suficiente para que haya intolerancia política. Este concepto es muy poco trabajado desde la ciencia política pero si ha sido tratado, en cierto modo, por las ciencias de la comunicación desde la misma vinculación entre los medios y las ideologías totalitarias. Según un profesor alemán, Iring Fetscher, la intolerancia se produce básicamente porque las personas poseen ciertas creencias políticas o religiosas que en sí mismas no se constituyen en un hecho verídico, por lo que no las tienen lo suficientemente arraigadas, $\mathrm{y}$ así, cualquier forma de pensar que sea diferente produce inseguridad, provocando 
su odio para reafirmarlas (Fetscher, 1999). Sin embargo, esa explicación es, en cierto modo, equivocada; la corrección proviene de una profesor de la Universidad de los Andes, quién en su conferencia sobre la tolerancia desde la perspectiva liberal dice acertadamente que la intolerancia se produce porque las personas que son adeptas a cierta ideología o religión creen que esta es la verdad única e indiscutible, por lo que entrarán en conflicto ante los contradictores (Jaramillo Uribe, 2002). Eso es exactamente lo que ocurre en Venezuela: las partes son tan radicales que piensan que la contraparte es el enemigo que hay que combatir. Lo que no ha pasado -por ahora- es que el ambiente político en el país desemboque en violencia, que, por decirlo así, es la forma extrema en la que se manifiesta la intolerancia política.

3. El mismo Estado venezolano puede convertirse en un Estado autoritario. Formalmente, aún se puede decir que Venezuela es una democracia liberal porque hay elecciones, cierta participación de grupos opositores - aunque se ha reducido desde la elección de Maduro como presidente-, legislaciones y división tripartita del poder -a pesar de que estos están controlados por el chavismo- pero, por la ambigüedad misma del concepto de "democracia", no se puede admitir que estas son las únicas formas en las que se manifiesta. Por ello se dice que el Estado puede convertirse en uno de corte autoritario: en su afán de extender la "revolución bolivariana", quizá, las autoridades pueden ir más allá de las limitaciones a la libertad de expresión y a la manifestación en la Asamblea Nacional y actuar de la manera propia en la que lo hacen los regímenes autoritarios mediante persecuciones, desapariciones, espionaje, entre otros. Aunque el ambiente lo amerita, es poco probable que ocurra a corto plazo porque cualquier acto de esta naturaleza podría provocar violencia política entre las partes, y además, caería en el extremo de la contradicción al conocer sobre la "defensa" que los chavistas han hecho de la democracia.

\section{Conclusiones}

¿Por qué las limitaciones a las libertades de expresión y de comunicación son la razón principal del intento de acallar a la oposición? sería bueno decir por qué estas limitaciones e intentos de monopolio son la razón principal por la que el gobierno venezolano ha intentado acallar a la oposición: 
1. Los medios de comunicación venezolanos han tenido una influencia tan fuerte que incluso se puede decir que es mayor que el de los partidos políticos y del mismo gobierno venezolano. Como se mencionó anteriormente, antes de la llegada de Hugo Chávez al poder, el sector privado, que era su mayor propietario, imponía la agenda política del país y por ello la información que transmitían era sesgada y poco objetiva. El régimen chavista aprovechó, casi con eficacia, dicha influencia y la utilizó en beneficio propio; no ha cambiado para nada esta imposición de la agenda, sino quien la realiza, y además, se ha hecho con las limitaciones y restricciones mencionadas anteriormente.

2. Como se explicó a lo largo de este texto, los medios de comunicación pueden ser útiles para extender una ideología política en toda la población, pero para ello se debían tener ciertas condiciones como la debilidad de la democracia, un contexto de crisis política y una cultura política favorable al surgimiento de líderes carismáticos. Todas estas las tenía Venezuela; en los ochenta y los noventa atravesó por un crisis económica que aumento los índices de pobreza y de desigualdad social, los partidos tradicionales eran deslegitimados por no cumplir con las expectativas de las ciudadanía y el gobierno era poco eficaz. De nuevo, el chavismo utilizó casi con eficacia todo esto para extender su ideología política dentro de la población, pero su objetivo solo se ha cumplido posiblemente a la mitad.

3. Las limitaciones a las libertades de expresión y de comunicación han buscado impedir que los opositores tengan un espacio para manifestarse y así lograr los objetivos anteriores. Hay que admitir que estos tienen cierta responsabilidad por la situación de los medios ya que han publicado informaciones que son similares a las del gobierno, en tanto que han promovido la intolerancia política (Human Rights Watch, 2012). Pero también ha sido responsabilidad del oficialismo ya que busca implantar una ideología que, para su infortunio, no la comparte la mitad de la sociedad del país.

Los medios de comunicación, por las razones mencionadas, ya no cumplen su función de ser los espacios de discusión sobre las problemáticas de la sociedad, sino que han entrado a ser solo el instrumento de una ideología para imponer el "socialismo del 
siglo XXI", y hacer que todos, sin condición, la acepten como la única forma legítima -y quizá, hasta legal- de pensar. En este artículo no se realiza propuesta alguna de solución porque las partes son irreconciliables y el problema es tan fuerte que, quizá, ninguna otra pueda ser útil para ser aplicada. Los analistas de nuestro país han dicho que la situación es completamente ilegitima, pero hay que aceptar que ello depende de los mismos venezolanos hacer que los medios sirvan a los intereses de la gente, como debería ser, o dejar que sigan siendo solo un instrumento del poder de algunos.

\section{Referencias}

Arias García, A. (2012). "Hugo Chávez y la crisis de representación político-partidaria en Venezuela". Trans-pasando Fronteras, núm. 2, pp. 65-83. doi:http://dx.doi. org/10.18046/retf.i2.1324

"Chávez logra un cuarto mandato como presidente para estar 20 años en el poder". En: El Pais. Fecha de consulta: 26 de Julio de 2013 en: http://internacional.elpais.com/ internacional/2012/10/07/actualidad/1349633710_923402.html.

"El legado social de Hugo Chávez". En: BBC Mundo. Fecha de consulta: 23 de Julio de 2013 en: http://www.bbc.co.uk/mundo/noticias/2013/03/130306_venezuela_chavez_ legado_social_vh.shtml.

"Jefa de fiscales argentina dictamina que ley de medios es constitucional". En: Vanguardia Liberal. Fecha de consulta: 20 de Junio de 2013 en:http:/www.vanguardia.com/ actualidad/mundo/216136-jefa-de-fiscales-argentina-dictamina-que-ley-de-medios-esconstitucional.

"Maduro expuso a Santos 'elementos' que estropearon la relación: Jaua". En: El Tiempo. Fecha de consulta: 26 de Julio de 2013 en: http://www.eltiempo.com/mundo/ latinoamerica/ARTICULO-WEB-NEW_NOTA_INTERIOR-12943883.html.

"Presidente Santos alcanza los dos millones de seguidores en Twitter". En: El Espectador. Fecha de consulta: 26 de Julio de 2013 en: http://www.elespectador.com/noticias/ actualidad/articulo-433237-presidente-santos-alcanza-los-dos-millones-de-seguidorestwitter.

"Se cierra venta de televisora privada 'Globovisión"'. En: El Tiempo. Fecha de consulta: 1 de Julio de 2013 en: http://www.eltiempo.com/mundo/latinoamerica/ARTICULO-WEB-NEW_NOTA_INTERIOR-12796422.html. 
"Venta de Globovisión se concretará en las 'próximas horas". En: El Espectador. Fecha de consulta: 1 de Julio de 2013 en: http:/www.elespectador.com/noticias/elmundo/articulo-419763-venta-de-globovision-se-concretara-proximas-horas.

"Violencia irrumpe en la Asamblea Nacional de Venezuela". En: El País. Fecha de consulta: 26 de Julio de 2013 en: http:/internacional.elpais.com/internacional/2013/05/01/actualidad/1367370533_014786.html.

Bacalao, Mariana. "Venezuela: medios de comunicación en un contexto polarizado". En: Investigadores de la Comunicación de Venezuela. Fecha de consulta: 15 de Junio de 2013 en: http://www.invecom.org/eventos/2009/pdf/bacalao_m.pdf.

Balle, Francis (1994). Comunicación y Sociedad. Evolución y análisis comparativo de los medios. Bogotá D.C., Colombia: Tercer Mundo Editores.

Bermúdez, Emilia (2007). "Libertad de expresión y hegemonía en Venezuela. De la hegemonía de los medios a la hegemonía del Estado", en: Quórum Académico, 4 (2). $42-60$.

Campbell, Mónica. "Medios privados venezolanos se debilitan bajo el asedio de Chávez". En: Comité para la Protección de Periodistas. Fecha de consulta: 15 de Junio de 2013 en: http://www.cpj.org/es/2012/08/medios-privados-venezolanos-se-marchitanbajo-ased.php.

Castillo Briceño, Javier (2003). "Hugo Chávez y los medios de comunicación: la guerra 'hiperreal' venezolana" en: Historia y Comunicación Social, (8), 21-34.

Fetscher, Iring (1999). La tolerancia. Una pequeña virtud imprescindible para la democracia. Panorama histórico y problemas actuales. Barcelona, España: Gedisa Editorial.

García Nivia, Mario Sergio (2008). "Opinión pública. El desalentador caso de Venezuela y Ecuador” en: Revista Perspectiva, (19), 32-34.

Gómez Buendía, Hernando. "Retos del periodismo en una democracia. Cada país tiene los medios de se merece" en: Varios (2004). Poder y Medio. Bogotá D.C., Colombia: Editora Aguilar

Human Rights Watch. "Concentración y abuso de poder en la Venezuela de Chávez". En: Human Rights Watch. Fecha de consulta: 15 de Junio de 2013 en: http://www.hrw. org/sites/default/files/reports/venezuela0812sp.pdf.

Jaramillo Uribe, Jaime. “Tolerancia e intolerancia. Sus orígenes y consecuencias en 
las historia de la civilización occidental" en: Varios (2002). Pluralismo, tolerancia y conflicto. Bogotá D.C., Colombia: Instituto de Humanidades, Departamento de Filosofía, Universidad de la Sabana.

Loreti, Damián (2005). América Latina y la libertad de expresión. Bogotá D.C., Colombia: Grupo Editorial Norma.

O’Donnell, Guillermo (2007). Disonancias. Críticas democráticas a la democracia. Buenos Aires, Argentina: Prometeo Libros.

Pasquali, Antonio (2007). "La libertad de expresión bajo el régimen chavista: mayo de 2007” en: Signo y Pensamiento, 26 (50), 265-275.

Sánchez Ruiz, Enrique (2005). Medios de comunicación y democracia. Bogotá D.C., Colombia: Grupo Editorial Norma.

Weber, Max. Economía y Sociedad. México D.F., México, Fondo de Cultura Económica, 1987. 
